DR. M ROSARIO RUEDA (Orcid ID : 0000-0002-3941-9031)

Article type : Paper

\title{
Metacognitive scaffolding boosts cognitive and neural benefits following executive attention training in children
}

\author{
J. Paul Pozuelos ${ }^{1}$, Lina M. Combita ${ }^{1}$, Alicia Abundis ${ }^{1}$, Pedro M. Paz-Alonso ${ }^{2}$, Ángela \\ Conejero $^{1}$, Sonia Guerra ${ }^{1} \&$ M. Rosario Rueda ${ }^{1 \#}$
}

${ }^{1}$ Dept. of Experimental Psychology and Center for Research on Mind, Brain and Behavior (CIMCYC), Universidad de Granada, Spain

2 BCBL, Basque Center on Cognition, Brain and Language, Spain

\# Corresponding author:

M. Rosario Rueda, PhD

Dept. Experimental Psychology

Center for Research on Mind, Brain and Behavior (CIMCYC)

Universidad de Granada

Campus Cartuja s/n

18071 Granada, Spain

Phone: +34 958249609

email: rorueda@ugr.es

\section{Research highlights}

- This paper presents a novel approach to cognitive training with preschool children, where process-based computerized training is combined with metacognitive scaffolding.

- Compared to process-based training alone, adult-provided metacognitive scaffolding produces a similar near-transfer effect of executive attention training to inhibitory control, but increased far-transfer to fluid intelligence.

- Metacognitive training also produced a significant change on the fronto-central ERP component associated with conflict processing, which, in turn, predicts gains on intelligence scores following training.

This article has been accepted for publication and undergone full peer review but has not been through the copyediting, typesetting, pagination and proofreading process, which may lead to differences between this version and the Version of Record. Please cite this article as doi: $10.1111 /$ desc. 12756

This article is protected by copyright. All rights reserved. 
- This study provides evidence that process-based training benefits can be boosted by providing children with scaffolding on the use of metacognitive strategies while performing training exercises.

\begin{abstract}
Interventions including social scaffolding and metacognitive strategies have been used in educational settings to promote cognition. In addition, increasing evidence shows that computerized process-based training enhances cognitive skills. However, no prior studies have examined the effect of combining these two training strategies. The goal of this study was to test the combined effect of metacognitive scaffolding and computer-based training of executive attention in a sample of typically developing preschoolers at the cognitive and brain levels. Compared to children in the regular training protocol and an untrained active control group, children in the metacognitive group showed larger gains on intelligence and significant increases on an electrophysiological index associated with conflict processing. Moreover, changes in the conflict-related brain activity predicted gains in intelligence in the metacognitive scaffolding group. These results suggest that metacognitive scaffolding boosts the influence of process-based training on cognitive efficiency and brain plasticity related to executive attention.
\end{abstract}

\title{
Introduction
}

The question of whether mental skills can be improved by means of cognitive training has been posed for decades and regained interest in the past years. Cognitive training refers to the process of improving cognition by means of practice and/or intentional instruction, and can be classified as either process-based or strategy-based (Jolles \& Crone, 2012). Process-based training consists in the repetitive practice of one or various tasks taxing particular cognitive processes, whereas strategy-based training provides participants with instructions to develop and enhance their knowledge about task-relevant procedures and strategies (i.e. scaffolding).

This article is protected by copyright. All rights reserved. 
Executive Attention (EA) is the aspect of attention that is involved in the voluntary regulation of thoughts and behavior, involving processes of conflict-detection and resolution, cognitive flexibility and inhibitory control (Posner \& DiGirolamo, 1998; Rueda, Pozuelos, \& Cómbita, 2015). This concept partially overlaps with other constructs related to the control of behavior, such as executive control and executive functions, and is a key aspect in the development of selfregulation (Rueda, Posner, \& Rothbart, 2005). An increasing body of evidence shows that children's executive attention and associated brain function can be enhanced with training (Diamond \& Lee, 2007; Karbach \& Unger, 2014). The majority of studies have used computerized exercises designed to practice processes, such as executive attention (including conflict processing, attentional flexibility and inhibitory control; Rueda, Rothbart, McCandliss, Saccomanno, \& Posner, 2005), task switching (Karbach \& Kray, 2009; Kray, Karbach, Haenig, \& Freitag, 2011), working memory (Jaeggi, Buschkuehl, Jonides, \& Shah, 2011; Klingberg, 2010), and inhibitory control (Benikos, Johnstone, \& Roodenrys, 2013; Thorell, Lindqvist, Bergman Nutley, Bohlin, \& Klingberg, 2009). Consistently, this research has shown that process-based training of executive processes is an effective way to improve children's cognitive control. However, several other studies have reported contradictory results, claiming that the training effects only produces specific short-term benefits that do not generalize to other cognitive domains (see Melby-Lervåg \& Hulme, 2012 for a review). Recent reviews of the topic point to a wide range of aspects that may account for the lack of consistency of training results, including individual variables (such as cognitive level at pre-intervention, temperament, or motivational factors), as well as variables related to the type of intervention being used (Karbach \& Unger, 2014). Therefore, more information is needed in order to understand whether training is an effective means to enhance cognitive performance and which type of interventions produce larger benefits.

Studies using neuroimaging technology have provided additional evidence of the impact of training at the level of brain function. Research with adults and children has shown that process-based training leads to changes at the level of brain activation (Olesen, Westerberg, \& 
Klingberg, 2004) and functional connectivity (Jolles, van Buchem, Crone, \& Rombouts, 2013; Astle et. al., 2015). Further, EEG studies have revealed that training influences the timing and topography of electrophysiological markers of executive attention such as the N2 or later components. The N2 is an event-related potential whose amplitude is modulated by increasing conflict between possible response alternatives, such as in the flanker or other conflict-inducing tasks (van Veen \& Carter, 2002). In adults, conflict-related N2 is characterized by a frontocentral negativity that peaks around $200-300 \mathrm{~ms}$ after the stimulus onset, and is associated with activation arising in the anterior cingulate cortex (ACC), one of the main nodes of the executive attention network (Carter \& van Veen, 2007; Veen \& Carter, 2002). Depending on the particular task being used for inducing conflict (e.g. flanker, Go-NoGo, Stroop) the conflict-related modulation of the ERPs amplitude may occur in time-windows later than the N2. For instance, with shape flanker tasks (Checa et al., 2014) and Stroop-like tasks (Szűcs \& Soltész, 2012), conflict modulation has been observed in a positive deflection of the ERP that follows the N2. Higher-conflict trials produce a more negative amplitude of this positive component compared to low-conflict or no-conflict trials in midfrontal leads, which is interpreted as greater engagement of the executive attention brain network for resolving conflict (Szűcs \& Soltész, 2012; Checa et al., 2014). Developmental studies have shown that the conflict-related N2 shows an age-related decrease in latency and amplitude (Lo et al., 2018). Using a child-friendly version of a shape flanker task in which children are asked to identify the shape (round or square) of a robot that is flanked by distracting robots of the same (i.e., congruent, no-conflict trials) or the other (i.e., incongruent, conflict trials), Checa and colleagues (2014) found that 11 to 13 -year-olds, as well as adults, showed a clear conflict-related amplitude modulation around 400 ms post-target, whereas younger children showed a much smaller effect at around $600 \mathrm{~ms}$ post-target at frontal midline channels. Also, with a fish flanker task in which participant had to identify the direction in which the central fish is pointing, adults show conflict-related modulation of the $\mathrm{N} 2$ at frontal (Fcz and Cz) midline leads, while 4 years-olds only show the conflict modulation in a late positive deflection occurring at about 600 
ms post-target in more anterior (Fz) frontal channels (Rueda et al., 2004). Following processbased training, preschool children appear to show a reduction in the latency of conflict-related components as well as a change in topography of the effect from anterior $(\mathrm{Fz})$ to more posterior (Fcz and Cz) frontal-midline channels (Rueda, Checa, \& Cómbita, 2012; Rueda, Rothbart, et al., 2005).

The transfer of process-based training benefits to non-trained tasks whose performance is thought to rely on the same process as the one trained (i.e. near-transfer) and transfer to related yet non-trained cognitive domains (i.e. far-transfer) has also been examined. Although research yields mix results, particularly in far transfer effects, a considerable number of previous attention and working memory training studies have been shown to produce gains in fluid intelligence (fIQ) in young children (Neville et al., 2013; Rueda et al., 2012), older children (Jaeggi et al., 2011; Klingberg, Forssberg, \& Westerberg, 2002), and adults (Jaušovec \& Jaušovec, 2012; Karbach \& Kray, 2009). Despite all this evidence, other studies have failed to find significant transfer effects of executive processes to fluid intelligence (Colom et al., 2013; Sarzyńska, Żelechowska, Falkiewicz, \& Nęcka, 2017) and argue that transfer to intelligence may need more sustained training, or that training might not impact on intelligence at the construct level but benefit more basic processes taxed by training activities. However, a compelling argument in favor of far-transfer between executive attention training and $f I Q$ skills is the overlap of cognitive processes and anatomical regions underlying both cognitive domains. Prior research has shown that the overlapping between processing components and brain regions is a necessary condition for the occurrence of transfer between tasks (Dahlin, Neely, Larsson, Bäckman, \& Nyberg, 2008). Studies addressing the neural basis of intelligence have highlighted a striking overlap between regions related to executive control and those activated by $g$ tests (Duncan, 2000; Hampshire, Thompson, Duncan, \& Owen, 2011). Moreover, there is evidence indicating that neural activity in the lateral PFC, a region thought to support reasoning, mediates the relationship between $f I Q$ and performance on tasks involving executive control (Gray, Chabris, \& Braver, 2003).

This article is protected by copyright. All rights reserved. 
While a relatively large bulk of research has focused on the effects of process-based interventions, a relatively small body of research studied the effects of strategy-based training programs. Strategy-based training studies are based primarily on providing guidance about analyzing tasks requirements and the best strategies to face them, often using explicit task instructions (e.g., prompting the use of mental imagery to increase memory). Such is the case of educational interventions designed to improve cognitive control mechanisms via scaffolding. Research has shown that metacognitive scaffolding improves formal instruction in school subjects (Kramarski \& Mevarech, 2003). Moreover, a few studies have observed beneficial effects of specific school curricula on children's executive control skills, such as the Montessori curriculum (Lillard \& Else-Quest, 2006). Also, a program based on Vygotsky's learning theory, that largely relies on peer and adult scaffolding, appears to enhance executive control at prekindergarten (Diamond, Barnett, Thomas, \& Munro, 2007), although the impact seems to be limited on children's academic abilities (Barnett et al., 2008). A recent randomized controlled trial involving kindergarten schools of different socioeconomic backgrounds showed that this curriculum may be particularly effective helping children of schools with increased indices of poverty in attention control and emotional regulation (Blair \& Raver, 2014). However, putative changes in brain mechanisms associated with strategy-based training are largely unknown.

Metacognition is a broad term encompassing both knowledge and regulation of mental activity, and can be divided into Metacognitive Control (MC) and Metacognitive Knowledge (MK) (Moshman, 2017; Nelson \& Narens, 1994; Schraw \& Moshman, 1995). MC has been closely linked to the executive control of attention, since both share underlying brain structures and rely on the voluntary regulation of cognition by means of monitoring (e.g. error detection) and control (e.g. conflict resolution, error correction, planning, inhibitory control) mechanisms (Fernandez-duque, Baird, \& Posner, 2000; Shimamura, 2008). On the other hand, MK consists primarily of a metalevel awareness of different types of knowledge about 1) the goals of particular tasks and the cognitive requirements necessary to achieve them (i.e. declarative knowledge), 2) how to execute the specific actions required in particular conditions (i.e. 
procedural knowledge), and 3) knowing why and when to implement actions to achieve goals (i.e. conditional knowledge) (Goldfus, 2012; Schraw \& Moshman, 1995). MK is continuously updated and enhanced by information coming from the conscious monitoring of cognition, the observation of one's own and other people's actions, and by interacting and communicating with others (Efklides, 2008). Therefore, language plays a critical role in MK because it is through language that people are able to reflect, draw inferences, communicate the content of their awareness, and make attributions about the relations between inner states, observable behavior, and action outcomes.

Several authors have underlined the importance of language and abstract representations for the emergence of self-regulation of cognition and behavior. Vygotsky (1978) and Luria (1965) claimed that social scaffolding provides children with experiences that boost the development and maturation of higher cognitive functions. When interacting with more capable individuals, children learn how to use language as a tool for creating abstract representations. This interaction supports the skills and knowledge that are just about to emerge in the child, which in turn helps children to move from being assisted by an adult when performing a new task to being able to perform it independently (Bodrova, Leong, \& Akhutina, 2011; Wood, Bruner, \& Ross, 1976).

Several studies have been conducted to characterize the developmental trajectories of metacognitive abilities (see Roebers, 2017 for a review). These studies have shown that the emergence of MC skills occurs between 3 to 5 years of age (Coughlin, Hembacher, Lyons, \& Ghetti, 2015; Kim, Paulus, Sodian, \& Proust, 2016; Lyons \& Ghetti, 2013). Also, it has been suggested that after 5 years children become more efficient in implementing monitoring abilities to improve their behavioral control and the selection of task strategies (Destan, Hembacher, Ghetti, \& Roebers, 2014). In addition, Munakata, Snyder, \& Chatham (2012) proposed that the transition between exogenous to endogenous driven self-regulation occurs with the emergence of the ability to actively maintain abstract representations in working 
memory. They argue that when children improve their ability to use and internalize abstract representations they become more efficient in regulating top-down support for goal-relevant thoughts and behavior (Munakata et al., 2012). Several theories suggest that abstract representations in anterior lateral PFC regions provide top-down support to resolve competition between less abstract representations in more posterior regions of the PFC (Christoff \& Gabrieli, 2000), indicating that a gradual maturation of rostrolateral PFC may underlie children's ability to use abstract representations to control cognition and behavior (Bunge \& Zelazo, 2006).

An attempt to examine the contribution of reflection strategies to children's learning to perform the Dimensional Change Card Sort (DCCS) task was made by Espinet, Anderson, and Zelazo (2013). In their study, young children (2-4 years old) who failed to perform the task at pretraining were guided by an adult to reflect on relevant instructions and dimensions of the task in each particular trial, providing an example of a correct response, and then asking the child to perform the trial again with assistance. This guided training was made during a brief 15 (Exp. 2 and 3) or 30 (Exp. 1) minutes intervention, and the benefits were tested the following day on a different version of the same task using different stimuli. They found that children who received the reflection guidance showed improved performance of the task following the intervention, as well as a transferred benefit to false belief understanding, whereas children who only received corrective feedback or just practiced the task during intervention did not. Additionally, they observed that both the reflection training and the corrective feedback groups showed a reduction of the general amplitude of the N2 registered during children's performance of the task following the intervention.

In the present study, we sought to examine the effect of combining process-based executive attention training with adult-guided scaffolding aimed at promoting metacognition during training, and compare this intervention with either using only process-based training accompanied by corrective feedback, or an untrained active control group, in a randomized 
controlled trial with pre-school aged children. We aimed at designing a scaffolding script specifically devised to provide metacognitive feedback in order to foster children's ability to create abstract representations and to improve the performance of training exercises. Our expectation is that both trained groups would enhance the efficiency of executive control processes following intervention compared to the untrained group. As shown in previous studies, we expected near-transfer of process-based training to untrained but related tasks, as well as far-transfer to untrained executive functions (working memory) and fluid intelligence. However, a key prediction of our study is that using metacognitive scaffolding during training in the first group would boost both the near- and far-transfer effects. Promoting the use of metacognitive strategies related to both control of cognition (i.e. performance monitoring, planning, error correction, etc.; that is, metacognitive control) and awareness of self- and taskconditions (i.e. declarative, procedural and conditional metacognitive knowledge) that are necessary to face the challenges related to performing exercises in the training program are expected to cause increased training benefits. Further, we expected to observe the effect of training at the brain level. To this purpose, brain electrophysiological responses were registered while children performed a conflict-related child-friendly shape flanker task before and after intervention. Increased efficiency of performance in terms of modulation of the conflict-related late positive component was expected following training, with a larger impact on the metacognitive scaffolding group.

\section{Method}

\section{Participants}

A total of 107 five-year-old children were recruited from various kindergartens in Granada, Spain. Caregivers of all the children gave written consent to be involved in the study after being informed of its general purpose. Only children whose parents agreed to voluntary participation were included in the study. Prerequisites for participation were having normal or corrected-to-

This article is protected by copyright. All rights reserved. 
normal sensory capacities and no history of chronic illness and/or psychopathologies. Prior to undertaking the investigation, ethical approval was obtained from the Research Ethics Committee of the University of Granada. Children received a t-shirt with the logo of the lab, as well as small presents such as stickers, pencils, bouncing balls, etc., after completion of different tasks in each session, in appreciation for their participation in the study. Ten participants withdrew during the study and therefore their data were discarded for further processing. See Table 1 for a statistical description of the sample.

\section{Procedure}

A picture of the general procedure of the study is presented in Figure 1. Pre- and post-training assessment included a standardized test of intelligence for preschool children that comprises fluid (Matrices) and crystalized (Verbal) subscales (K-Bit; Kaufman and Kaufman, 1990), as well as lab tasks taxing inhibitory control (Simon Says task; Strommen, 1973) and working memory (WM, Working Memory Span backwards subtests of the WISC; Wechsler, 1991). The Simon Says task is based on the principles of a Go-NoGo task, where children have to comply with an instruction when preceded by the verbal cue "Simon Says" (e.g. Simon Says touch your head), and to inhibit the response when the cue is missing (e.g. touch your head). Counting the number of times children fail to inhibit the instruction when the cue is missing provides a measure of inhibitory control (IC). The WM backwards subscale of the WISC is a test of WM span that consists in asking children to memorize a set of numbers given by the experimenter and then repeat the numbers in reverse order. The dependent variable in this task is the number of items correctly recalled in reverse order. This pen and pencil assessment of IQ, IC, and WM was carried out in a suitable classroom at school.

Within four days after the evaluation at the school, a second evaluation session was carried out at the developmental cognitive neuroscience lab of the CIMCYC, at the University of Granada. In this session, caregivers brought children to the lab and children conducted a child-friendly

This article is protected by copyright. All rights reserved. 
version of the flanker task (Checa, Castellanos, Abundis-Gutiérrez, \& Rueda, 2014) designed to measure interference control while recording brain activation by means of a high-density EEG system (128-channel Geodesic Sensor Net; www.egi.com). Once fitted with the net of electrodes, and it was properly registering brain's electrical signals, children were presented with the flanker task. At the beginning of each trial, a fixation cross was displayed at the center of the screen for a variable duration randomly selected between 600 to $1200 \mathrm{~ms}$. The target stimuli consisted of a row of five cartoon robots presented at the center of the screen either above or below the fixation cross. Participants were asked to indicate the shape of the robot in the middle (either round or square) by pressing a corresponding button. Flanking robots could be of the same (congruent) or different (incongruent) shape as that of the robot in the middle. The task consisted of a total of 144 trials divided into six blocks. Flanking robots were congruent in half of the trials and the congruency condition was randomly selected for each trial. In order to control the difficulty of the task, the target presentation time was adjusted in each trial according to children's performance in the previous trial. When an error was made or the response was given off time, the target duration was increased by $50 \mathrm{~ms}$ in the following trial. Alternatively, the target duration in trial $\mathrm{n}+1$ was decreased by $50 \mathrm{~ms}$ when the response in trial $\mathrm{n}$ was correct. Following the response, a 600 ms-lasting feedback was provided. The feedback consisted of a visual animation of the central figure plus an auditory word ("yes" for correct responses, "no" for incorrect responses, and "late" for omission or off-time responses).

The protocol of the two PRE-intervention evaluation sessions was repeated within a week of completing the intervention phase for POST evaluation. A member of the research team who was blinded to the experimental group of the participant conducted evaluation sessions at both pre- and post- time points. Caregivers were informed about the design of the experiment prior to providing written consent as to being involved in the study, and remained blind to the group allocation of their child throughout the experiment.

This article is protected by copyright. All rights reserved. 
After pre-training assessment, participants were randomly assigned to one of three intervention groups: Training + Metacognitive scaffolding (MT), Training + Corrective feedback (T), or Active Control (AC) groups. Groups were matched for age, gender distribution, and average composite intelligence (see Table 1). Series of random allocation of participants to each intervention group were carried out up until the groups did not differ in these variables.

Participants in the MT group carried out an adaptive training program (see below) and received individualized metacognitive scaffolding during training sessions from an adult experimenter. A metacognitive scaffolding script was designed for each of the exercises included in the training program (see Supplementary Material), and members of the research team who conducted the training sessions were trained on the use of the script prior to the start of the study. In addition, children received encouraging feedback (i.e. "good job!", “you are doing great!", “Great! you have advanced to level x in this game!", etc.) according to their performance throughout the training sessions. Participants in the T group carried out the exact same adaptive training program as the MT but only received instructions as to how to play each task and encouraging (same as the one used with MT group) and corrective (either "good job!", "correct! ", or "careful, you made a mistake!" "your response was not correct this time") feedback related to their performance (see Table S1 and supplementary material for further information on the scaffolding script). Finally, the AC group carried out a non-adaptive version of the training program consisting of only the first three levels of each training task with no further increase in difficulty. The AC group also received instructions about each task and encouraging feedback during task performance. Children who completed the training requirements before exhausting the session time were allowed to watch child-friendly cartoon shorts to complete the remaining time of the session. Intervention with each group comprised a total of ten 45-minute sessions carried out over a 4week period. Intervention sessions took place individually for each participant in a quiet room at school.

This article is protected by copyright. All rights reserved. 


\section{EEG recording and data processing}

EEG was recorded using a 128-channel Geodesic Sensor Net 4.2 (EGI Software: www.egi.com).

The EEG signal was acquired using a 100 to $0.01 \mathrm{~Hz}$ band-pass filter and digitized at $250 \mathrm{~Hz}$. Impedance for all channels was kept below $50 \mathrm{~K} \Omega$. Pre-processing of continuous data was performed in EEGLAB version 13.2.2 (Delorme \& Makeig, 2004). EEG data were filtered using a finite impulse response (FIR) band pass filter with $0.3 \mathrm{~Hz}$ high-pass and $30 \mathrm{~Hz}$ low-pass cutoffs (Passband gain: 99.0\% (-0.1 dB), stopband gain: 1.0\% (-40.0 dB), rolloff: $0.29 \mathrm{~Hz})$. Bad channels were replaced by spherical interpolation provided that no more than 10 channels were identified as bad channels and were distributed over the scalp. Average re-reference was computed. Artifacts in the continuous EEG were identified by visual inspection and manually removed before running Independent Component Analysis (ICA) to detect and correct eye blink artifacts. After artifact removal, the event-related potentials (ERP) were processed using ERPLAb toolbox (Lopez-Calderon \& Luck, 2014). Continuous data were segmented into targetlocked epochs of $1200 \mathrm{~ms}$ long (-200 to $1000 \mathrm{~ms}$ ) with a pre-stimulus baseline correction of $200 \mathrm{~ms}$. Artifact-free segments were averaged across conditions and participants within each training group. A per-subject criterion of a minimum of 15 artifact-free segments per experimental condition was established in order to be included in the grand-average for each training group. A total of sixty-nine children reached that criterion and where used in the analysis, 26 at the $\mathrm{AC}$ group (trials congruent $\mathrm{M}=44.07, \mathrm{SD}=1.34$; incongruent $\mathrm{M}=42.27, \mathrm{SD}=$ 0.74 ), 23 at the MT Group (trials congruent $\mathrm{M}=44.22, \mathrm{SD}=0.21$; incongruent $\mathrm{M}=44.64, \mathrm{SD}=$ 0.91 ), and 20 at the $\mathrm{T}$ group (trials congruent $\mathrm{M}=44.72, \mathrm{SD}=1.90$; incongruent $\mathrm{M}=44.49, \mathrm{SD}=$ 0.71). We conducted a series of one-way ANOVAs in order to test significant differences in fIQ, VIQ, composite IQ and age (in months) between the total sample and the artifact-free EEG sample, and between the artifact-free EEG sample and the discarded sample. Results show no significant difference between the samples (all F's $<1$ ) in fIQ (Mean for total $=105.12$, EEG $=$ 104.60, discarded $=106.45)$, in vIQ (Mean for total $=107.83, \mathrm{EEG}=108.43$, discarded $=105.36$ ),

This article is protected by copyright. All rights reserved. 
Composite IQ $($ Mean for total $=104.98, \mathrm{EEG}=105.09$, discarded $=104.18)$ and age $($ Mean for total $=63.8, \mathrm{EEG}=64.4$, discarded $=62.1)$.

\section{Training program}

The training program used in the present study was the same as used by Rueda et al. (2012; also described at Rueda et al., 2007). The program consisted of 14 computerized exercises divided into 6 categories: (1) Tracking/Anticipatory; (2) Attention Focusing/Discrimination; (3) Conflict Monitoring/Resolution; (4) Inhibitory control; (5) Task Switching; and (6) Sustained Attention. For the current study, we designed three additional exercises that were included as follows: two in the category of Conflict Monitoring/ Resolution, and one in the category of Inhibitory Control. The exercises were programmed such as task difficulty being adjusted to the child's improving performance over a number of blocks of trials (i.e. adaptive training). In order to progress from one level of difficulty to the next, children were required to correctly complete a minimum number of consecutive trials ( 3 in most exercises). A description of each exercise included in the training program is presented in Table 2.

\section{Metacognitive scaffolding}

Based on the scaffolding principles, we developed a metacognitive scaffolding script (MSS) aiming at establishing a dynamic reflective dialogue between the trainer and the child during training. The MSS was composed by questions intending to assist children's causal reasoning by guiding their learning on how to extract the relevant features of a given task and integrate them into abstract representations that could help improving the performance of training exercises. Children were encouraged to verbally externalize procedures such as 1) detecting the relevant features of the exercise (i.e. declarative knowledge), 2) reflecting on possible strategies to perform the task initially and improve their performance in advanced stages (i.e. procedural 
knowledge), and 3) becoming aware of their mistakes and think about how to prevent errors from happening in subsequent trials right after an error was committed by the child (i.e. conditional knowledge). By encouraging this verbalization, we aimed at fostering children's emergent ability to create and use abstract representations to improve their performance in training exercises. An example of the MSS is provided at Supplementary Material.

\section{Results}

Children who showed a percentage of error 2 standard deviations (SD) above the mean in any of the assessment measures (see final $n$ for each task on Table 3) or had a score 2 SD below the mean on the intelligence ( $n=1$ at MT group) test were excluded from analyses of those particular measures.

\section{Training performance}

Differences in training performance between MT and T groups were tested. We found a significant difference between groups in the percentage of errors committed during training $(\mathrm{t}(1,62)=-2.03, \mathrm{p}=.045)$ and a marginal difference in the total number of trials needed to complete the training program $(\mathrm{t}(1,62)=-1.93, \mathrm{p}=.058)$. Children in the MT-Group committed less errors and needed less trials in order to complete the training program as compared with children in the T-Group (error percentage: mean $=168.54, \mathrm{SD}=81.84$ and mean $=217.71, \mathrm{SD}=$ 109.74, No. of trials mean $=1079.21, \mathrm{SD}=291.25$ and mean $=1192.38, \mathrm{SD}=151.66$ respectively for MT and T groups).

This article is protected by copyright. All rights reserved. 


\section{Training effects}

\section{Behavioral measures}

Table 3 presents means and SDs of pre- and post-intervention sessions scores obtained in each assessment task. We calculated standardized gain scores ((Mean $\left.\left.{ }_{P R E}-M_{\text {Mean }}{ }_{P O S T}\right) / S D_{\text {pooled PRE }}\right)$ for each intervention group in order to compare the size of training-related gains across all the measurements taken in the study. To examine pre- vs. post-training changes in each task of the battery (i.e. fluid (fIQ) and verbal (vIQ) subscales and composite IQ of the K-BIT, WM span, IC, and flanker interference effects) we conducted a series of 3 (Intervention Group: MT, T, and AC) $\mathrm{x} 2$ (Session: pre- vs, post-intervention) mixed-model ANOVAs with Intervention Group as the between-subject factor. In addition, given a priori hypotheses on gains following training, planned comparisons were carried out to test for changes in performance between the pre- and post-intervention sessions for each measure in each intervention group.

Regarding intelligence, a significant main effect of Session was found for the fIQ $(F(1,92)=9.54$, $\left.\mathrm{p}=.002, \eta^{2} \mathrm{p}=0.09\right)$ and composite IQ $\left(\mathrm{F}(1,92)=7.74, \mathrm{p}=.006, \eta^{2} \mathrm{p}=0.07\right)$ scores. Also, $\mathrm{a}$ significant Intervention Group $x$ Session interaction was observed for both fIQ $(F(2,92)=4.50, p$ $\left.=.013, \eta^{2}=0.09\right)$ and composite IQ $\left(F(2,92)=3.46, p=.035, \eta^{2} p=0.07\right)$ scores. No statistically significant main effect of Session or Intervention Group x Session interaction was found for vIQ scores (both Fs $<1$ ). We conducted a series of planned contrasts to further examine the effect of Intervention Group on fIQ and composite IQ scores. The observed increase in fIQ was significant for both the MT $(F(1,92)=12.98, p<.001)$ and $\mathrm{T}(\mathrm{F}(1,92)=4.78, \mathrm{p}=.031)$ groups. However, only the MT group showed a significant pre to post increase on the composite IQ score $(F(1,92)$ $=12.35, \mathrm{p}<.001)$. In order to compare gains values between intervention groups we calculated Cohen's d ( $d=[($ Mean score Trained GroupPOST - Mean score Trained GroupPRE) - (Mean score Control GroupPOST - Mean score Control GroupPRE)]/ Pooled SDPRE) as in Carlson \& Schmidt (1999). Cohen's d values denoted a large intervention effect when comparing the MT and AC groups (fIQ $d=0.84$, composite IQ $d=0.80$ ), a moderate effect when comparing the MT 
and T groups (fIQ $d=0.41$, composite IQ $d=0.42)$ and the T and AC groups on the fIQ score $(d=$ 0.44), and a small effect when contrasting T and AC groups on the composite IQ score $(d=0.27)$.

Analyses of the WM scores revealed a marginal main effect of Session $(F(1,94)=3.25, p=.07$, $\left.\eta^{2} p=0.03\right)$. No significant main effect of Group $(F(2,94)=1.55, p=.21)$ or Intervention Group $x$ Session interaction $(\mathrm{F}<1)$ were found. $\mathrm{T}$-tests contrasts testing training gains indicated that the pre- to post-training increased score was marginal only for the MT group $(F(1,94)=2.92, p=$ .09) but not for the other two groups (Fs $<1)$.

The Simon says task proved to be rather difficult for children in our study. A total of 36 children (12 in the MT group, 8 in the T group, and 16 in the AC group) did not pass the criteria for understanding instructions and showed above $70 \%$ errors in experimental trials, therefore they were excluded from further analysis of this particular task. Inhibitory control scores results revealed a significant main effect of Session $\left(F(1,58)=11.79, p=.001, \eta^{2} p=0.16\right)$, indicating a decrease of inhibition errors in the post- relative to the pre-intervention session. No significant Intervention Group x Session interaction was found $(\mathrm{F}<1)$. However, planned contrasts testing training gains revealed significant post- vs pre-intervention decreases in inhibition errors only for the MT $(F(1,58)=4.29, \mathrm{p}=.04)$ and $\mathrm{T}$ groups $(\mathrm{F}(1,58)=8.23, \mathrm{p}=$ $.005)$, but not for the AC group $(\mathrm{F}(1,58)=1.32, \mathrm{p}=.25)$.

Finally, we also analyzed flanker conflict scores obtained during performance of the flanker task in the pre- and post-EEG-assessment sessions. Flanker conflict scores were calculated by subtracting the median reaction times (RT) and percentage of errors of trials with congruent flankers from those of trials with incongruent flankers. The ANOVA of conflict effects with RT revealed a significant main effect of Session $(F(1,70)=7.75, p<.01)$, indicating higher conflict scores in the pre- $(M=58.60, S D=76.30)$ compared to the post-intervention $(M=31, S D=$ 52.73) sessions. However, neither the effect of the Intervention Group nor the Intervention Group x Session interaction was significant (both $\mathrm{F}<1$ ). Likewise, the ANOVA conducted with 
the conflict scores for the percentage of errors did not reveal any statistically significant main effect or interactions (all $\mathrm{F}<1$ ).

Intervention effect on fluid reasoning in function of baseline scores

In order to examine the possible influence of pre-level reasoning skills on training-related gains, we calculated the mean fIQ score at pre-training for each intervention group and divided participants between above mean (high fIQ-baseline group) and below mean (Low fIQ-baseline group). The resulting groups were MT-high ( $\mathrm{n}=18)$, MT-low $(\mathrm{n}=14), \mathrm{T}$-high $(\mathrm{n}=16), \mathrm{T}$-low $(\mathrm{n}=15)$, AC-high $(\mathrm{n}=18)$, AC-low $(\mathrm{n}=15)$. Then we conducted a 3 Intervention Group (MT, T and AC Group) x 2 Baseline-fIQ Group (High vs. Low) x 2 Session (Pre vs Post) mixed ANOVAs with fIQ gain (post-intervention minus pre-intervention score) as dependent measure. Results revealed a significant main effect of Baseline-fIQ Group $\left(F(1,89)=6.48, p=.01, \eta^{2} p=0.06\right)$ and Intervention Group $\left(F(1,89)=9.55, p=.002, \eta^{2} p=0.09\right)$. More importantly, we found a significant Intervention Group X Session interaction $\left(F(2,89)=4.65, p=.01, \eta^{2} p=0.09\right)$, indicating that pre to post gains in fIQ were significant for both the low $(F(1,89)=6.33, p=.01)$ and high baseline subgroups in the $\mathrm{MT}(\mathrm{F}(1,89)=6.73, \mathrm{p}=.01)$. In contrast, only the lowbaseline subgroup showed a significant gain effect in the T-group $(F(1,89)=4.80, p=.03)$. Finally, no significant differences were found for either the low-baseline $(\mathrm{F}<1)$ or for the highbaseline $(F(1,89)=2.04, p=0.15)$ subgroups in the AC group (see Figure 3).

\section{Electrophysiological data}

Target-locked ERPs per Flanker Congruency condition and Intervention Group are presented in Figure 4. The topographic distribution of conflict-related amplitude matched what was expected from prior studies using child-friendly flanker tasks with children, showing the larger effects at frontal midline channels. Thus, ERPs at frontal midline (average of leads 11 and 15 in the EGI's 
sensor net) and central midline (average of leads 6 and Cz in the EGI's sensor net) were analyzed and plotted in Figure 4. Following the distribution of conflict-related effects observed in prior Non-parametric dependent-samples, permutation t-tests (Brainstorm, Monte Carlo method, 1,000 permutations; Tadel, Baillet, Mosher, Pantazis, \& Leahy, 2011) were conducted for each sample along the entire ERP segment in order to test differences in amplitude between congruent and incongruent conditions. Areas that showed a significant difference in amplitude in at least 10 consecutive samples $(40 \mathrm{~ms})$ are shadowed ( $<<.05$ light gray; $\mathrm{p}<.01$ dark gray; arrowheads point to the time in which significant differences between conditions first appear (i.e. the latency of the effect); see Fig. 4a).

In line with prior studies, pre-training ERPs show that the latency of the congruency effect extends between about $450 \mathrm{~ms}$ and $850 \mathrm{~ms}$ after stimuli onset and is present particularly at frontal electrode sites, which is consistent with a previous study carried out with the exact same task (Checa et al., 2014). To test the effect of intervention on conflict-related ERPs, we conducted non-parametric dependent-samples permutation t-tests for each sample along the entire ERP segment for frontal (Fz) and central (Fcz/Cz) leads at each session for each experimental group. Results show larger differences in amplitude between congruency conditions for the MT and T groups at central electrode sites compared with children in the AC group. Also, we found a decrease in latency of the conflict-related amplitude modulation particularly in central electrode sites only for trained children (Figure $4 \mathrm{a}$ and $4 \mathrm{~b}$ ). To further characterize training-related changes on ERPs we calculated the area of the congruency effect (i.e. area of amplitude difference between congruent and incongruent conditions) within a timewindow ranging from 450-850 ms and introduced it as dependent variable into a 3 (Intervention Group: MT, T and AC) x 2 (Session: Pre vs Post) x 2 (Lead Position: frontal vs central) mixed-model ANOVA. Results revealed a significant main effect of Lead Position $\left(F(1,66)=6.56, p=.012, \eta^{2} p=0.09\right)$ indicating larger area of congruent vs incongruent difference in frontal $($ mean $=1.15, \mathrm{SD}=1.23)$ than central $($ mean $=0.87, \mathrm{SD}=0.79)$ leads. Also, we found a marginal Session $x$ Intervention Group interaction $\left(F(2,66)=2.31, p=0.10, \eta^{2} p=\right.$ 
0.09). Subsequent planned contrasts revealed a significant increase in area of congruent vs incongruent difference in the post-intervention compared to the pre-intervention session at central leads $(F(1,66)=6.26, p=.014)$ for the MT-group. In contrast, there were no significant changes in the area between pre- and post-training sessions in any of the electrode sites for either the T-group or the AC-group (see Fig 4c).

\section{Relationship between behavioral and brain effects of intervention}

In order to examine the contribution of training-related changes in ERP indexes to observed gains in intelligence we computed a training gain index using the ERP congruency area (i.e., cong. vs. incong. area difference at post-training minus cong. vs. incong. area difference at pretraining) and conducted linear regression analyses including gains in intelligence as the dependent variable and the ERP congruency area index as the predictor. Results revealed that, only for the MT-group, post-training area gain was a significant predictor of training gains in composite IQ $\left(\mathrm{R}^{2}=.318, \beta=.564 ; \mathrm{p}=.008\right.$; see Fig. 5), and a marginal predictor of training gains in the fIQ score $\left(\mathrm{R}^{2}=.125, \beta=.353 ; \mathrm{p}=.10\right)$.

\section{Discussion}

Results of the study revealed increased gains in fluid reasoning following process-based training of executive attention + metacognitive scaffolding than when using process-based training alone, although both training strategies produced benefits in IC and fluid IQ as compared to an untrained active control group. Additionally, we found a significant change in a brain index of executive attention (i.e. conflict-related modulation of a frontally distributed late positive component) following metacognitive-coached training, but not process-based training alone. Further, the increase in the conflict-related effect (i.e. amplitude difference between 
congruent and incongruent trials) observed in midline central leads significantly contributes to predicting increases in IQ scores following training.

As compared to an active control intervention, training of executive attention showed a modest impact on the ability to inhibit response tendencies in the Simon Says task, a well-used measure of inhibitory control in young children (Carlson, 2005), but did not show an effect on WM (see Table 3 and Figure 2). Near-transfer of executive attention training to IC was expected in our study. Two training exercises (Farmer and Robots) in the training program were specifically designed to train response inhibition, and yet most of the exercises included in the program (see Table 2) involve IC to some degree. However, WM was not directly targeted by any of the exercises in the training program, although it was a component on advanced levels of two training tasks (Portraits and Shapes; see Table 2). The different load of the two processes in the training program may explain differences in the impact of training on IC and WM scores in our study. Also, it is important to bear in mind that the auditory backward WM span procedure used in our study is a challenging task for 5 years-olds and increases of one span unit represent a considerable rise in WM load for children this age. The difficulty of the task may have undermined the potential effect of training.

Training also produced increased fluid reasoning scores leaving crystallized intelligence unchanged, with the impact of training on fluid IQ being larger for the MT group as compared to the T group. Benefits of executive control training on fIQ have been repeatedly found in previous research with both children (Jaeggi et al., 2011; Neville et al., 2013; Rueda, et al., 2005) and adults (Jaeggi, Buschkuehl, Jonides, \& Perrig, 2008; Karbach \& Kray, 2009) and were hence expected. In addition, previous studies have shown that metacognitive abilities help to improve performance in problem-solving (Whitebread, 1999) and WM (Autin \& Croizet, 2012). Further, it has been suggested that training of specific metacognitive strategies (i.e. rehearsal, semantic coding, and imagining) has a positive influence on WM performance (Carretti, Borella, \& De Beni, 2007). Our data provide evidence for the beneficial influence of metacognitive scaffolding 
during the training itself. We found that children in the MT intervention group committed fewer errors and needed fewer trials while completing the training program as compared to the noncoached training group. This indicates that performance during training was improved by the interactive adult-child feedback dialogue designed to enhance metacognition. Most importantly, despite completing fewer training trials, children in the MT intervention showed a larger increase in fluid reasoning scores following training than children in the $\mathrm{T}$ or $\mathrm{AC}$ groups. The fact that metacognitive + process-based training has similar impact as process-based training alone on IC but larger impact on reasoning intelligence suggests that the metacognitive scaffolding helps particularly the process of generalization of training to other domains. The process-based training strategy taxes basic cognitive skills such as attention and executive functions, which constitute building blocks of superior cognitive functions including reasoning, planning and decision making (Diamond, 2013). Compared to the T group, the increased gain of the MT group was driven by a greater improvement in fIQ of children with high-baseline reasoning skills, who benefited more from the inclusion of metacognitive scaffolding as compared to children with low-reasoning skills at baseline. Demetriou et al. (2008) and others have presented a hierarchical structural model of intelligence where higher-order reasoning abilities build upon lower-level processes related to cognitive control and speed of processing. The current findings suggest that children with high-baseline reasoning skills take out more of scaffolding during intervention predictably because they were better able to use guided metacognitive strategies required to create, update, maintain, and implement abstract representations in order to improve task performance during training.

With respect to the impact of training on brain function, we found an increase in the area of the conflict effect (i.e. increased differential brain activation for congruent vs incongruent trials) from pre- to post-intervention session that was observed only for the MT group. Previous studies had shown that executive attention-training influences the timing, amplitude, and topographic distribution of the ERP effects related to conflict monitoring during the performance of a flanker task (Rueda et al., 2012; 2005). Likewise, other studies have 
previously shown changes in attention-related electrophysiological indices following cognitive interventions aimed at improving selective (Stevens, Fanning, Coch, Sanders, \& Neville, 2008) and executive attention (Millner, Jaroszewski, Chamarthi, \& Pizzagalli, 2012). Also, in the Espinet et al. (2013) study mentioned before, a general (not conflict-related) reduction in the amplitude of the N2 during the performance of the DCCS, a task requiring attention flexibility in order to adapt to changing rules, was observed following training with reflective and corrective feedback. In the current study, the extent of the influence of cognitive intervention at the brain level depended on the training strategy. Our results revealed a decrease in latency and an increase in the congruency effect at the frontally-distributed positive deflection of the ERP following the $\mathrm{N} 2$ at the post-session, observed only for children in the MT intervention group. Children in the T group showed a similar tendency which did not reach statistical significance. Developmental studies examining brain dynamics of executive attention with ERPs have shown that the amplitude of the N2 component associated with high-conflict trials decreases with age (Lo, 2018). However, in the Lo et al. meta-analysis, the differential amplitude of the ERP for high vs low-conflict trials could not be tested because most studies do not report information of brain activation for low- or no-conflict trials. Using the exact same task that was used in the current study, it was previously reported that young children show delayed and smaller conflict-related modulation of the ERP amplitude in frontal channels as compared to older children and adults (Checa et al., 2014). Young children often fail to show conflict-related modulation in early ERP components such as the N2 (Abundis-Gutiérrez et al., 2014); instead they show a delayed effect in more anterior (Fz and AF) channels (Rueda et al., 2004). These delayed effects were also observed in the pre-intervention session in all three intervention groups (see ERPs in Figure 4a). However, with age, the conflict-related modulation of early ERP components (around the N2 time-window) increases in magnitude and progressively moves from a broader anterior to a more focused posterior frontal distribution (Abundis-Gutiérrez et al., 2014). Also, consistent with electrophysiological data, behavioral studies have shown a notable development of executive attention during preschool years evidenced by large 
decreases in conflict scores between 3 and 6 years of age (Rueda, Posner, et al., 2005) followed by a protracted reduction of conflict during late childhood (Pozuelos, et al., 2014). Following intervention, children in the MT group, showed an earlier and increased conflict-related effect in the positive deflection following the N2. According to previous developmental data with the same conflict task, the pattern of brain activation produced by the MT training resembles a more adult-like activation, suggesting that the impact of intervention on brain function resembles the changes produced by natural development. Noteworthy, observed changes in brain markers of executive attention were not paralleled by significant improvements in the performance of the flanker task. Flanker conflict scores in RT at pre-intervention were around $60 \mathrm{~ms}$, which is consistent with what has been previously found in children of the same age. These scores where reduced to about $30 \mathrm{~ms}$ in the post-intervention session in all three intervention groups, an effect size that is similar to that of adults when performing the same task (Checa et al., 2014). Therefore, we believe that the performance of the task might have reached ceiling the second time children faced the task, thus hindering the sensibility of the measurement to show an effect of the intervention. In this context, using brain measures may provide a more sensitive test of training effects because changes in underlying brain processes can be seized in the absence of observable effects at the behavior level.

Importantly, the reported increase in the conflict-related area following intervention predicts intelligence gains shown by the MT group. One possible explanation for this is that metacognitive scaffolding strengthened the ability to use abstract representations, which in turn enhance the efficiency of cognitive control mechanisms at the brain level. In line with this interpretation, recent evidence shows the relevance of processing efficiency in nodes of the executive attention network (i.e. the dorsal ACC and anterior insula) when it comes to explaining individual differences in intelligence (Hilger, Ekman, Fiebach, \& Basten, 2017). Additionally, previous studies indicate that the activation of abstract representations promotes proactive control in children (Chevalier, Martis, Curran, \& Munakata, 2015) and improves taskswitching efficiency (Snyder \& Munakata, 2010). Proactive control can be conceptualized as a

This article is protected by copyright. All rights reserved. 
form of early selection in which abstract representations of goal-relevant information are actively maintained, allowing individuals to optimally prepare the system before the occurrence of cognitively demanding events (Braver, 2012). The relation between reasoning skills and proactive control is supported by a study conducted by Burgess and Braver (2010), which showed that individuals with high fIQ activate proactive control mechanisms to a greater extent than those with low fIQ. Further, higher intelligence scores are related to more efficient brain activation of cognitive control mechanisms engaged by the flanker task (Liu, Xiao, Shi, Zhao, \& Liu, 2011). Therefore, these findings suggest that metacognitive scaffolding enhances the ability to create, maintain, and implement abstract representations supporting the efficiency of cognitive control mechanisms. We believe that the increased ability to use metacognitive strategies boosted the effects of process-based training and produced greater impact on the tactical and deliberate use of executive control processes at both behavioral and brain function levels.

Based on the research literature in psychological and educational science, Hirsh-Pasek and colleagues (2015) argue that children learn best when they are cognitively active and engaged, when learning experiences are meaningful and socially interactive, and when learning is guided by a specific goal. They also claim that the educational value of the increasingly popular computer-based programs and apps will depend on whether intervention programs are designed on the basis of these learning principles. Results from the current study provide evidence of the benefits of integrating process-based training with scaffolding as a method to improve metacognitive knowledge and reasoning skills. Our results provide evidence that it is possible to enhance the beneficial effects of cognitive training by means of metacognitive scaffolding. Further, this strategy enhances brain mechanisms underlying executive attention, which in turn contributes to gains in reasoning skills following intervention. Although more research is needed to replicate and extend our results, we think that the evidence provided represents promising ideas and methods that might assist the design of more effective cognitive interventions.

This article is protected by copyright. All rights reserved. 


\section{Acknowledgements}

Research presented in this paper was funded by a grant from the Spanish Research Agency (ref.

PSI2014-55833-P) awarded to MRR. We are also grateful to children and caregivers who

participated in the study.

\section{References}

Abundis-Gutiérrez, A., Checa, P., Castellanos, C., \& Rueda, M. R. (2014). Electrophysiological correlates of attention networks in childhood and early adulthood. Neuropsychologia, 57, 78-92. http://doi.org/10.1016/j.neuropsychologia.2014.02.013

Astle, D. E., Barnes, J. J., Baker, K., Colclough, G. L., \& Woolrich, M. W. (2015). Cognitive training enhances intrinsic brain connectivity in childhood. Journal of Neuroscience, 35(16), 62776283. http://doi.org/10.1523/JNEUROSCI.4517-14.2015

Autin, F., \& Croizet, J.-C. (2012). Improving working memory efficiency by reframing metacognitive interpretation of task difficulty. Journal of Experimental Psychology: General, 141(4), 610-618. http://doi.org/10.1037/a0027478

Barnett, W. S., Jung, K., Yarosz, D. J., Thomas, J., Hornbeck, A., Stechuk, R., \& Burns, S. (2008). Educational effects of the Tools of the Mind curriculum: A randomized trial. Early Childhood Research Quarterly. http://doi.org/10.1016/j.ecresq.2008.03.001

Benikos, N., Johnstone, S. J., \& Roodenrys, S. J. (2013). Short-term training in the Go/Nogo task: behavioural and neural changes depend on task demands. International Journal of Psychophysiology: Official Journal of the International Organization of Psychophysiology, 87(3), 301-12. http://doi.org/10.1016/j.ijpsycho.2012.12.001

Blair, C., \& Raver, C. C. (2014). Closing the Achievement Gap through Modification of Neurocognitive and Neuroendocrine Function: Results from a Cluster Randomized Controlled Trial of an Innovative Approach to the Education of Children in Kindergarten. PLoS ONE, 9(11), e112393. http://doi.org/10.1371/journal.pone.0112393

Bodrova, E., Leong, D. J., \& Akhutina, T. V. (2011). When everything new is well-forgotten old: Vygotsky/Luria insights in the development of executive functions. New Directions for Child and Adolescent Development, 2011(133), 11-28. http://doi.org/10.1002/cd.301

Braver, T. S. (2012). The variable nature of cognitive control: a dual mechanisms framework. Trends in Cognitive Sciences, 16(2), 106-13. http://doi.org/10.1016/j.tics.2011.12.010

Bunge, S. A., \& Zelazo, P. D. (2006). Brain-Based Account of the Development of Rule Use in Childhood. Psychological Science, 15(3), 118-121.

Burgess, G. C., \& Braver, T. S. (2010). Neural mechanisms of interference control in working memory: effects of interference expectancy and fluid intelligence. PloS One, 5(9), e12861. http://doi.org/10.1371/journal.pone.0012861

Carlson, K. D., \& Schmidt, F. L. (1999). Impact of experimental design on effect size: Findings from the research literature on training. Journal of Applied Psychology, 84(6), 851-862. http://doi.org/10.1037/0021-9010.84.6.851

This article is protected by copyright. All rights reserved. 
Carlson, S. M. (2005). Developmentally Sensitive Measures of Executive Function in Preschool Children. Developmental Neuropsychology, 28(2), 595-616.

http://doi.org/10.1207/s15326942dn2802_3

Carretti, B., Borella, E., \& De Beni, R. (2007). Does strategic memory training improve the working memory performance of younger and older adults? Experimental Psychology, 54(4), 311-320. http://doi.org/10.1027/1618-3169.54.4.311

Carter, C. S., \& van Veen, V. (2007). Anterior cingulate cortex and conflict detection: an update of theory and data. Cognitive, Affective \& Behavioral Neuroscience, 7(4), 367-79. Retrieved from http://www.ncbi.nlm.nih.gov/pubmed/18189010

Checa, P., Castellanos, M. C., Abundis-Gutiérrez, A., \& Rueda, M. R. (2014). Development of neural mechanisms of conflict and error processing during childhood: implications for selfregulation. Frontiers in Psychology, 5(April), 326. http://doi.org/10.3389/fpsyg.2014.00326

Chevalier, N., Martis, S. B., Curran, T., \& Munakata, Y. (2015). Metacognitive Processes in Executive Control Development: The Case of Reactive and Proactive Control. Journal of Cognitive Neuroscience, 27(6), 1125-1136. http://doi.org/10.1162/jocn_a_00782

Christoff, K., \& Gabrieli, J. D. E. (2000). The frontopolar cortex and human cognition: Evidence for a rostrocaudal hierarchical organization within the human prefrontal cortex. Psychobiology, 28(2), 168-186. http://doi.org/10.3758/BF03331976

Colom, R., Román, F. J., Abad, F. J., Shih, P. C., Privado, J., Froufe, M., ... Jaeggi, S. M. (2013). Adaptive n-back training does not improve fluid intelligence at the construct level: Gains on individual tests suggest that training may enhance visuospatial processing. Intelligence, 41(5), 712-727. http://doi.org/10.1016/j.intell.2013.09.002

Coughlin, C., Hembacher, E., Lyons, K. E., \& Ghetti, S. (2015). Introspection on uncertainty and judicious help-seeking during the preschool years. Developmental Science, 18(6), 957-971. http://doi.org/10.1111/desc.12271

Dahlin, E., Neely, A. S., Larsson, A., Bäckman, L., \& Nyberg, L. (2008). Transfer of learning after updating training mediated by the striatum. Science (New York, N.Y.), 320(5882), 1510-2. http://doi.org/10.1126/science.1155466

Delorme, A., \& Makeig, S. (2004). EEGLAB: an open source toolbox for analysis of single-trial EEG dynamics including independent component analysis. Journal of Neuroscience Methods, 134(1), 9-21. http://doi.org/10.1016/j.jneumeth.2003.10.009

Demetriou, A., Mouyi, A., \& Spanoudis, G. (2008). Modelling the structure and development of $\mathrm{g}$. Intelligence, 36(5), 437-454. http://doi.org/10.1016/j.intell.2007.10.002

Destan, N., Hembacher, E., Ghetti, S., \& Roebers, C. M. (2014). Early metacognitive abilities: The interplay of monitoring and control processes in 5- to 7-year-old children. Journal of Experimental Child Psychology, 126, 213-228. http://doi.org/10.1016/j.jecp.2014.04.001

Diamond, A., \& Lee, K. (2007). Interventions Shown to Aid Executive Function Development in Children 4 to 12 Years Old. Science, 333(6045), 959-964. http://doi.org/10.1126/science.1204529

Duncan, J. (2000). A Neural Basis for General Intelligence. Science, 289(5478), 457-460. http://doi.org/10.1126/science.289.5478.457

Efklides, A. (2008). Metacognition. European Psychologist, 13(4), 277-287. http://doi.org/10.1027/1016-9040.13.4.277

Espinet, S. D., Anderson, J. E., \& Zelazo, P. D. (2013). Reflection training improves executive

This article is protected by copyright. All rights reserved. 
function in preschool-age children: Behavioral and neural effects. Developmental Cognitive Neuroscience, 4, 3-15. http://doi.org/10.1016/j.dcn.2012.11.009

Fernandez-duque, D., Baird, J. A., \& Posner, M. I. (2000). Executive Attention and Metacognitive Regulation. Consciousness and Cognition, 307, 288-307.

http://doi.org/10.1006/ccog.2000.0447

Goldfus, C. (2012). Intervention through metacognitive development: A case study of a student with dyslexia and comorbid attention deficit disorder (ADD). Journal of Languages and Culture, 3(3), 56-66. http://doi.org/10.5897/JLC11.042

Gray, J. R., Chabris, C. F., \& Braver, T. S. (2003). Neural mechanisms of general fluid intelligence. Nature Neuroscience, 6(3), 316-22. http://doi.org/10.1038/nn1014

Hampshire, A., Thompson, R., Duncan, J., \& Owen, A. M. (2011). Lateral prefrontal cortex subregions make dissociable contributions during fluid reasoning. Cerebral Cortex (New York, N.Y. : 1991), 21(1), 1-10. http://doi.org/10.1093/cercor/bhq085

Hilger, K., Ekman, M., Fiebach, C. J., \& Basten, U. (2017). Efficient hubs in the intelligent brain: Nodal efficiency of hub regions in the salience network is associated with general intelligence. Intelligence, 60, 10-25. doi: https://doi.org/10.1016/j.intell.2016.11.001

Hirsh-Pasek, K., Zosh, J. M., Golinkoff, R. M., Gray, J. H., Robb, M. B., \& Kaufman, J. (2015). Putting Education in "Educational" Apps. Psychological Science in the Public Interest, 16(1), 3-34. http://doi.org/10.1177/1529100615569721

Hulme, C., \& Melby-Lervåg, M. (2012). Current evidence does not support the claims made for CogMed working memory training. Journal of Applied Research in Memory and Cognition, 1(3), 197-200. http://doi.org/10.1016/j.jarmac.2012.06.006

Jaeggi, S. M., Buschkuehl, M., Jonides, J., \& Perrig, W. J. (2008). Improving fluid intelligence with training on working memory. Proceedings of the National Academy of Sciences of the United States of America, 105(19), 6829-33. http://doi.org/10.1073/pnas.0801268105

Jaeggi, S. M., Buschkuehl, M., Jonides, J., \& Shah, P. (2011). Short- and long-term benefits of cognitive training. Proceedings of the National Academy of Sciences of the United States of America, 108(25), 10081-6. http://doi.org/10.1073/pnas.1103228108

Jaušovec, N., \& Jaušovec, K. (2012). Working memory training: improving intelligence--changing brain activity. Brain and Cognition, 79(2), 96-106.

http://doi.org/10.1016/j.bandc.2012.02.007

Jolles, D. D., \& Crone, E. a. (2012). Training the developing brain: a neurocognitive perspective. Frontiers in Human Neuroscience, 6(April), 76. http://doi.org/10.3389/fnhum.2012.00076

Jolles, D. D., van Buchem, M. a, Crone, E. a, \& Rombouts, S. a R. B. (2013). Functional brain connectivity at rest changes after working memory training. Human Brain Mapping, 34(2), 396-406. http://doi.org/10.1002/hbm.21444

Karbach, J., \& Kray, J. (2009). How useful is executive control training? Age differences in near and far transfer of task-switching training. Developmental Science, 12(6), 978-90. http://doi.org/10.1111/j.1467-7687.2009.00846.x

Karbach, J., \& Unger, K. (2014). Executive control training from middle childhood to adolescence. Frontiers in Psychology, 5(May), 390.

http://doi.org/10.3389/fpsyg.2014.00390

Kim, S., Paulus, M., Sodian, B., \& Proust, J. (2016). Young Children's Sensitivity to Their Own Ignorance in Informing Others. PLOS ONE, 11(3), e0152595.

http://doi.org/10.1371/journal.pone.0152595

This article is protected by copyright. All rights reserved. 
Klingberg, T. (2010). Training and plasticity of working memory. Trends in Cognitive Sciences, 14(7), 317-24. http://doi.org/10.1016/j.tics.2010.05.002

Klingberg, T., Forssberg, H., \& Westerberg, H. (2002). Training of working memory in children with ADHD. Journal of Clinical and Experimental Neuropsychology, 24(6), 781-91. http://doi.org/10.1076/jcen.24.6.781.8395

Kramarski, B., \& Mevarech, Z. R. (2003). Enhancing Mathematical Reasoning in the Classroom: The Effects of Cooperative Learning and Metacognitive Training. American Educational Research Journal, 40(1), 281-310. http://doi.org/10.3102/00028312040001281

Kray, J., Karbach, J., Haenig, S., \& Freitag, C. (2011). Can task-switching training enhance executive control functioning in children with attention deficit/-hyperactivity disorder? Frontiers in Human Neuroscience, 5(January), 180. http://doi.org/10.3389/fnhum.2011.00180

Lillard, A., \& Else-Quest, N. (2006). The early years. Evaluating Montessori education. Science (New York, N.Y.), 313(5795), 1893-4. http://doi.org/10.1126/science.1132362

Liu, T., Xiao, T., Shi, J., Zhao, D., \& Liu, J. (2011). Conflict control of children with different intellectual levels: an ERP study. Neuroscience Letters, 490(2), 101-6. http://doi.org/10.1016/j.neulet.2010.12.035

Lo, S. L. (2018). A meta-analytic review of the event-related potentials (ERN and N2) in childhood and adolescence: Providing a developmental perspective on the conflict monitoring theory. Developmental Review, 48, 82-112. doi: https://doi.org/10.1016/j.dr.2018.03.005

Lopez-Calderon, J., \& Luck, S. J. (2014). ERPLAB: an open-source toolbox for the analysis of event-related potentials. Frontiers in Human Neuroscience, 8(April), 213. http://doi.org/10.3389/fnhum.2014.00213

Luria, A. R. (1965). L.S. Vygotsky and the problem of localization of functions. Neuropsychologia, 3(4), 387-392. http://doi.org/10.1016/0028-3932(65)90012-6

Luria, A. R. (2002). L . S . Vygotsky and the Problem of Functional Localization. Journal of Russian and East European Psychology, 40(1), 17-25.

Lyons, K. E., \& Ghetti, S. (2013). I Don't Want to Pick! Introspection on Uncertainty Supports Early Strategic Behavior. Child Development, 84(2), 726-736. http://doi.org/10.1111/cdev.12004

Melby-Lervåg, M., \& Hulme, C. (2012). Is Working Memory Training Effective? A Meta-Analytic Review. Developmental Psychology, 49(2), 270-291. http://doi.org/10.1037/a0028228

Millner, A. J., Jaroszewski, A. C., Chamarthi, H., \& Pizzagalli, D. a. (2012). Behavioral and electrophysiological correlates of training-induced cognitive control improvements. NeuroImage, 63(2), 742-53. http://doi.org/10.1016/j.neuroimage.2012.07.032

Moshman, D. (2017). Metacognitive Theories Revisited. Educational Psychology Review, 1-8. http://doi.org/10.1007/s10648-017-9413-7

Munakata, Y., Snyder, H. R., \& Chatham, C. H. (2012). Developing Cognitive Control: Three Key Transitions. Current Directions in Psychological Science, 21(2), 71-77. http://doi.org/10.1177/0963721412436807

Nelson, T. O., \& Narens, L. (1994). Why investigate metacognition? In J. Metcalfe \& A. P. Shimamura (Eds.), Metacognition: Knowing about knowing (pp. 1-25). Cambridge, MA: The MIT Press.

Neville, H. J., Stevens, C., Pakulak, E., Bell, T. A., Fanning, J., Klein, S., \& Isbell, E. (2013). Family-

This article is protected by copyright. All rights reserved. 
based training program improves brain function, cognition, and behavior in lower socioeconomic status preschoolers. Proceedings of the National Academy of Sciences, 110(29), 12138-12143. http://doi.org/10.1073/pnas.1304437110

Neville, H. J., Stevens, C., Pakulak, E., Bell, T. A., Fanning, J., Klein, S., \& Isbell, E. (2013). Familybased training program improves brain function, cognition, and behavior in lower socioeconomic status preschoolers. Proceedings of the National Academy of Sciences of the United States of America, 110(29), 12138-43. http://doi.org/10.1073/pnas.1304437110

Olesen, P. J., Westerberg, H., \& Klingberg, T. (2004). Increased prefrontal and parietal activity after training of working memory. Nature Neuroscience, 7(1), 75-9. http://doi.org/10.1038/nn1165

Posner, M. I., \& DiGirolamo, G. J. (1998). Executive attention: Conflict, target detection, and cognitive control. In R. Parasuraman (Ed.), The attentive brain (pp. 401-423). Cambridge, MA: MIT Press.

Pozuelos, J. P., Paz-Alonso, P. M., Castillo, A., Fuentes, L. J., \& Rueda, M. R. (2014). Development of attention networks and their interactions in childhood. Developmental Psychology, 50(10), 2405-15. http://doi.org/10.1037/a0037469

Roebers, C. M. (2017). Executive function and metacognition: Towards a unifying framework of cognitive self-regulation. Developmental Review, 45, 31-51. http://doi.org/10.1016/j.dr.2017.04.001

Rueda, M. R., Checa, P., \& Cómbita, L. M. (2012). Enhanced efficiency of the executive attention network after training in preschool children: immediate changes and effects after two months. Developmental Cognitive Neuroscience, 2 Suppl 1, S192-204. http://doi.org/10.1016/j.dcn.2011.09.004

Rueda, M. R., Posner, M. I., \& Rothbart, M. K. (2005). The development of executive attention: contributions to the emergence of self-regulation. Developmental Neuropsychology, 28(2), 573-94. http://doi.org/10.1207/s15326942dn2802_2

Rueda, M. R., Posner, M. I., Rothbart, M. K., \& Davis-Stober, C. P. (2004). Development of the time course for processing conflict: an event-related potentials study with 4 year olds and adults. BMC Neuroscience, 5, 39. http://doi.org/10.1186/1471-2202-5-39

Rueda, M. R., Pozuelos, J. P., \& Cómbita, L. M. (2015). Cognitive Neuroscience of Attention From brain mechanisms to individual differences in efficiency. AIMS Neuroscience, 2(4), 183202. http://doi.org/10.3934/Neuroscience.2015.4.183

Rueda, M. R., Rothbart, M. K., McCandliss, B. D., Saccomanno, L., \& Posner, M. I. (2005). Training, maturation, and genetic influences on the development of executive attention. Proceedings of the National Academy of Sciences of the United States of America, 102(41), 14931-6. http://doi.org/10.1073/pnas.0506897102

Sarzyńska, J., Żelechowska, D., Falkiewicz, M., \& Nęcka, E. (2017). Attention Training in Schoolchildren Improves Attention but Fails to Enhance Fluid Intelligence. Studia Psychologica, 59(1), 50-65. http://doi.org/10.21909/sp.2017.01.730

Schraw, G., \& Moshman, D. (1995). Metacognitive Theories. Educational Psychology Review, 7(4), 351-371.

Shimamura, A. P. (2008). A Neurocognitive Approach to Metacognitive Monitoring and Control. In J. Dunlosky \& R. Bjork (Eds.), Handbook of Memory and Metacognition (pp. 373-390). New Jersey: Erlbaum Publishers.

Snyder, H. R., \& Munakata, Y. (2010). Becoming self-directed: Abstract representations support endogenous flexibility in children. Cognition, 116(2), 155-167.

This article is protected by copyright. All rights reserved. 
http://doi.org/10.1016/j.cognition.2010.04.007

Stevens, C., Fanning, J., Coch, D., Sanders, L., \& Neville, H. (2008). Neural mechanisms of selective auditory attention are enhanced by computerized training: electrophysiological evidence from language-impaired and typically developing children. Brain Research, 1205, 55-69. http://doi.org/10.1016/j.brainres.2007.10.108

Szúcs, D., \& Soltész, F. (2012). Functional definition of the N450 event-related brain potential marker of conflict processing: a numerical stroop study. BMC Neuroscience, 13(1), 35. http://doi.org/10.1186/1471-2202-13-35

Tadel, F., Baillet, S., Mosher, J. C., Pantazis, D., \& Leahy, R. M. (2011). Brainstorm: a user-friendly application for MEG/EEG analysis. Computational Intelligence and Neuroscience, 2011, 879716. http://doi.org/10.1155/2011/879716

Thorell, L. B., Lindqvist, S., Bergman Nutley, S., Bohlin, G., \& Klingberg, T. (2009). Training and transfer effects of executive functions in preschool children. Developmental Science, 12(1), 106-13. http://doi.org/10.1111/j.1467-7687.2008.00745.x

Veen, V. Van, \& Carter, C. S. (2002). The Timing of Action-Monitoring Processes in the Anterior Cingulate Cortex. Journal of Cognitive Neuroscience, 593-602.

Vygotsky, L. S. (1978). Mind in Society: The Development of Higher Psychological Processes. Cambridge, MA: Harvard University Press. Retrieved from http://books.google.com/books?hl=en\&lr=\&id=Irq913lEZ1QC\&pgis=1

Waszak, F., Li, S.-C., \& Hommel, B. (2010). The development of attentional networks: crosssectional findings from a life span sample. Developmental Psychology, 46(2), 337-49. http://doi.org/10.1037/a0018541

Whitebread, D. (1999). Interactions between children's metacognitive abilities, working memory capacity, strategies and performance during problem-solving. European Journal of Psychology of Education, XIV(4), 489-507. http://doi.org/10.1007/BF03172975

Wood, D., Bruner, J. S., \& Ross, G. (1976). The role of tutoring in problem solving. Journal of Child Psychology and Psychiatry, 17(2), 89-100. Retrieved from http://www.ncbi.nlm.nih.gov/pubmed/932126

This article is protected by copyright. All rights reserved. 
Table 1. Descriptive statistics of participants

\begin{tabular}{llllll}
\hline & & \multicolumn{3}{c}{ Gender } & Mean Age \\
\cline { 3 - 6 } Group & $\boldsymbol{N}$ & Girls & Boys & (SD) & mean IQ (SD) \\
\hline MT & 33 & 14 & 19 & $63.4(7.84)$ & $104.7(13.89)$ \\
T & 31 & 13 & 18 & $63.5(7.15)$ & $104.9(14.72)$ \\
AC & 33 & 13 & 20 & $63.7(6.56)$ & $104.7(12.27)$ \\
\hline all & $\mathbf{9 7}$ & $\mathbf{4 0}$ & $\mathbf{5 7}$ & $\mathbf{6 3 . 6 ( 7 . 1 )}$ & $\mathbf{1 0 4 . 7}(\mathbf{1 3 . 6 2})$ \\
\hline
\end{tabular}

This article is protected by copyright. All rights reserved. 
Table 2. Description of training exercises

\begin{tabular}{|c|c|c|c|}
\hline Category & Exercise & Trained process & Brief Description \\
\hline \multirow{3}{*}{$\begin{array}{l}\text { Tracking / } \\
\text { Anticipation }\end{array}$} & Side & Target tracking & $\begin{array}{l}\text { Navigating a cartoon cat to reach areas of grass and avoid muddy areas, which get } \\
\text { progressively bigger }\end{array}$ \\
\hline & Chase & $\begin{array}{l}\text { Target tracking and } \\
\text { anticipation }\end{array}$ & $\begin{array}{l}\text { Anticipating where a cartoon duck that swims across a pond in a straight line will } \\
\text { come across in order to chasing it. In the highest levels of difficulty, the duck dives so } \\
\text { that its trajectory remains invisible. }\end{array}$ \\
\hline & Maze & Anticipation & Navigating a cartoon cat through a maze to get food. \\
\hline \multirow{2}{*}{$\begin{array}{l}\text { Attention focusing } \\
\text { / Discrimination }\end{array}$} & Portraits & $\begin{array}{l}\text { Focusing attention, } \\
\text { perceptual } \\
\text { discrimination and } \\
\text { working memory } \\
\end{array}$ & $\begin{array}{l}\text { Matching-to-sample exercise with cartoon pictures. Requires clicking on the one of } \\
\text { two pictures that looks exactly the same as the sample picture. In higher levels, the } \\
\text { sample picture disappears before the two choices appear on the screen and the child } \\
\text { is to keep in mind the attributes of the sample picture. }\end{array}$ \\
\hline & Shapes & $\begin{array}{l}\text { Focusing attention, } \\
\text { perceptual } \\
\text { discrimination and } \\
\text { working memory } \\
\end{array}$ & $\begin{array}{l}\text { A number of overlapping figures are presented and the child has to determine which } \\
\text { are the ones presented by clicking on the appropriate buttons displayed on the sides } \\
\text { of the screen. }\end{array}$ \\
\hline \multirow{3}{*}{$\begin{array}{l}\text { Conflict } \\
\text { monitoring and } \\
\text { resolution }\end{array}$} & Numbers & $\begin{array}{l}\text { Conflict monitoring } \\
\text { and resolution }\end{array}$ & $\begin{array}{l}\text { Two sets of numbers are presented and children have to click in the group composed } \\
\text { by the larger number of items. Trials can be congruent (larger group made up of } \\
\text { numbers of higher value) or incongruent (larger group made up of numbers of lower } \\
\text { value). }\end{array}$ \\
\hline & Value-not-size & $\begin{array}{l}\text { Conflict monitoring } \\
\text { and resolution }\end{array}$ & $\begin{array}{l}\text { Various numbers differing in size are presented on the screen. Children are asked to } \\
\text { click on the number of higher value disregarding the size. Size and value can be } \\
\text { congruent (the higher number is the larger in size) or incongruent (the higher } \\
\text { number is the smaller in size). }\end{array}$ \\
\hline & Teacher & Attentional flexibility & $\begin{array}{l}\text { The child is to classify items according to the rule presented by a teacher. Objects are } \\
\text { to be classified according to dimensions of shape, color and size. The rule changes at } \\
\text { different rates throughout the exercise. }\end{array}$ \\
\hline \multirow[b]{2}{*}{ Inhibitory control } & Farmer & Inhibitory control & $\begin{array}{l}\text { Cartoons animals (either sheep or wolfs) appear behind a bale of hay and children are } \\
\text { asked to quickly click only to sheep in order to bring them inside a fence. }\end{array}$ \\
\hline & Robots & Inhibitory control & $\begin{array}{l}\text { Children are to feed robots with metal pieces according to their shape and color in a } \\
\text { fast pace. They must avoid feeding each particular robot with pieces of non- } \\
\text { corresponding shape/color. }\end{array}$ \\
\hline $\begin{array}{l}\text { Sustained } \\
\text { attention }\end{array}$ & Frog & $\begin{array}{l}\text { Sustained attention } \\
\text { and preparation }\end{array}$ & $\begin{array}{l}\text { The child must press a key as fast as possible in order to help a frog catching flies that } \\
\text { come out of a bottle. The requirement to sustain attention is increased by enlarging } \\
\text { the interval of time between targets, and presence/absence of warning signals. }\end{array}$ \\
\hline
\end{tabular}

This article is protected by copyright. All rights reserved. 
Table 3. Means and Standard Deviations (SD) of Pre- and Post-intervention scores for all dependent measures. Planned contrasts indicate the F value for the significant comparisons between pre- and post-intervention scores. ${ }^{* * *} p<.001 ;{ }^{* *} p<.01 ;{ }^{*} p<.05 ; \approx p<.10$

\begin{tabular}{|c|c|c|c|c|c|c|c|c|c|}
\hline \multirow[b]{2}{*}{ Task } & \multirow[b]{2}{*}{ DV } & \multirow[b]{2}{*}{ Group } & \multirow{2}{*}{$\begin{array}{l}\text { Valid } \\
\mathbf{n}\end{array}$} & \multicolumn{2}{|c|}{ Pre-intervention } & \multicolumn{2}{|c|}{ Post-intervention } & \multirow{2}{*}{$\begin{array}{l}\text { Planned } \\
\text { contrasts } \\
\text { pre vs } \\
\text { post }\end{array}$} & \multirow{2}{*}{$\begin{array}{l}\text { Standardize } \\
\text { d gain }\end{array}$} \\
\hline & & & & Mean & (SD) & Mean & (SD) & & \\
\hline \multirow{9}{*}{$K-B I T$} & \multirow{3}{*}{$f I Q$} & MT & 32 & 104.8 & $(14.80)$ & 112.3 & $(11.12)$ & $12.98 * * *$ & 0.76 \\
\hline & & $\mathrm{T}$ & 31 & 104.1 & $(13.42)$ & 109.3 & $(9.69)$ & $4.78 *$ & 0.29 \\
\hline & & $\mathrm{AC}$ & 33 & 106.6 & $(12.28)$ & 105.7 & (12.19) & ns & -0.09 \\
\hline & \multirow{3}{*}{$v I Q$} & MT & 32 & 107.4 & $(11.20)$ & 110.8 & (12.61) & ns & 0.18 \\
\hline & & $\mathrm{T}$ & 31 & 108.3 & $(16.35)$ & 109.4 & $(12.91)$ & ns & 0 \\
\hline & & $\mathrm{AC}$ & 33 & 106.5 & $(16.09)$ & 106.3 & $(15.76)$ & ns & -0.01 \\
\hline & \multirow{3}{*}{ Composite IQ } & MT & 32 & 104.7 & $(12.27)$ & 110.9 & (11.93) & $12.35^{* * *}$ & 0.52 \\
\hline & & $\mathrm{T}$ & 31 & 104.7 & (13.89) & 108.2 & (11.08) & ns & 0.15 \\
\hline & & $\mathrm{AC}$ & 33 & 104.9 & $(14.7)$ & 104.6 & $(14.02)$ & ns & -0.02 \\
\hline \multirow{3}{*}{ WISC } & \multirow{3}{*}{$\begin{array}{l}\text { WM } \\
\text { backwards }\end{array}$} & MT & 33 & 2.2 & $(1.27)$ & 2.5 & $(1.14)$ & $2.92 \approx$ & 0.23 \\
\hline & & $\mathrm{T}$ & 31 & 2.0 & (1.39) & 2.1 & $(1.30)$ & ns & 0.16 \\
\hline & & $\mathrm{AC}$ & 33 & 1.8 & (1.14) & 1.9 & $(1.26)$ & ns & 0.03 \\
\hline \multirow{3}{*}{$\begin{array}{l}\text { Simon } \\
\text { Says }\end{array}$} & \multirow{3}{*}{$\begin{array}{l}\text { \% Inhibition } \\
\text { errors }\end{array}$} & MT & 21 & 28.0 & $(18.60)$ & 18.6 & $(19.30)$ & $4.29^{*}$ & 0.51 \\
\hline & & $\mathrm{T}$ & 23 & 32.6 & $(20.27)$ & 20.0 & (15.07) & $8.23^{* *}$ & 0.62 \\
\hline & & $\mathrm{AC}$ & 17 & 30.6 & $(21.35)$ & 24.7 & $(20.34)$ & ns & 0.28 \\
\hline \multirow{4}{*}{$\begin{array}{l}\text { Flanker } \\
\text { Task }\end{array}$} & \multirow{3}{*}{$\begin{array}{l}\text { Conflict score } \\
(R T)\end{array}$} & $\mathrm{MT}$ & 25 & 50 & (69) & 28 & (55) & ns & - \\
\hline & & $\mathrm{T}$ & 20 & 61 & (96) & 35 & (39) & ns & - \\
\hline & & $\mathrm{AC}$ & 28 & 64 & $(68)$ & 31 & $(60)$ & ns & - \\
\hline & Conflict score & MT & 25 & 7.2 & $(9.6)$ & 6.2 & $(6.0)$ & ns & - \\
\hline
\end{tabular}

This article is protected by copyright. All rights reserved. 

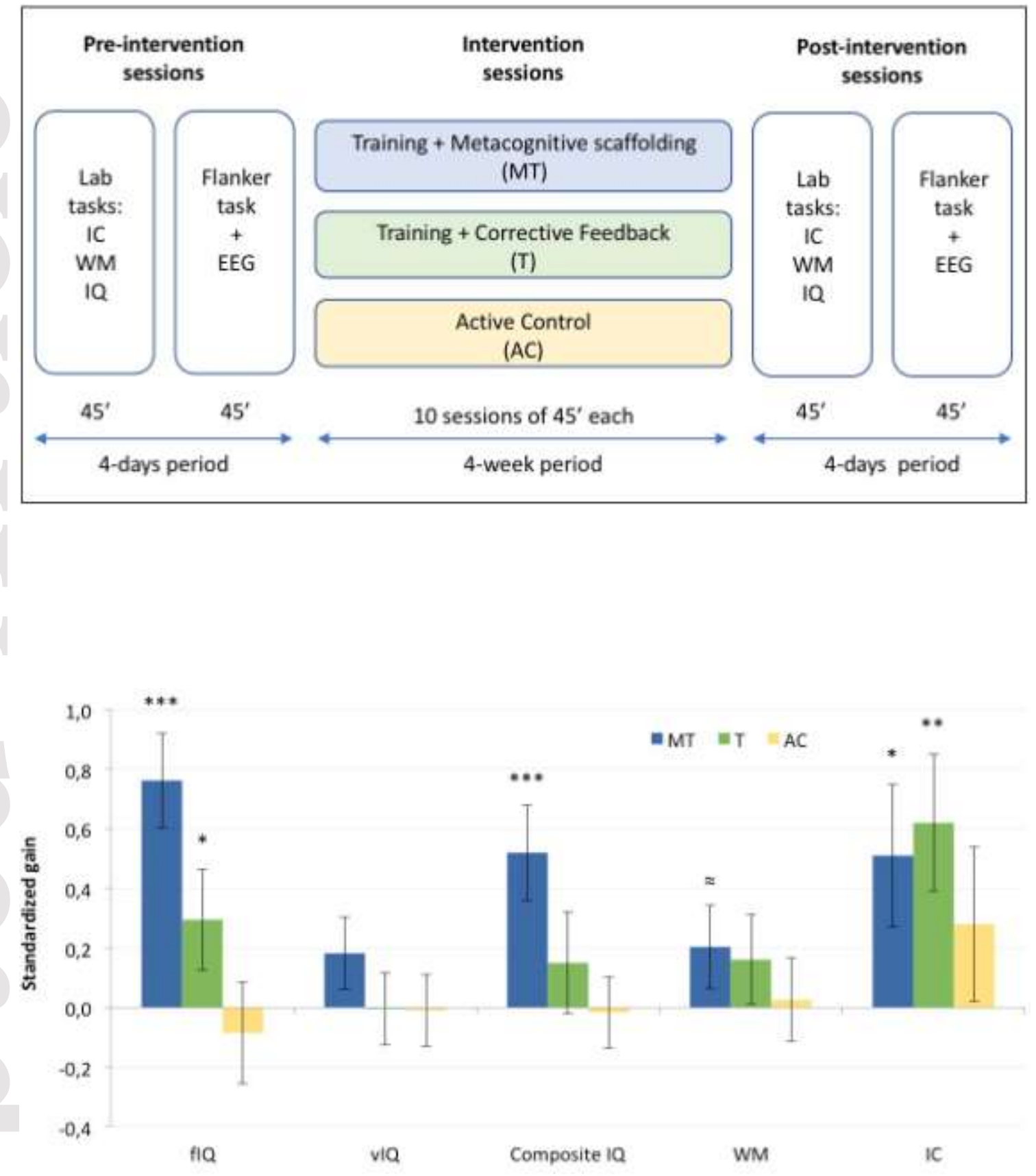

This article is protected by copyright. All rights reserved. 

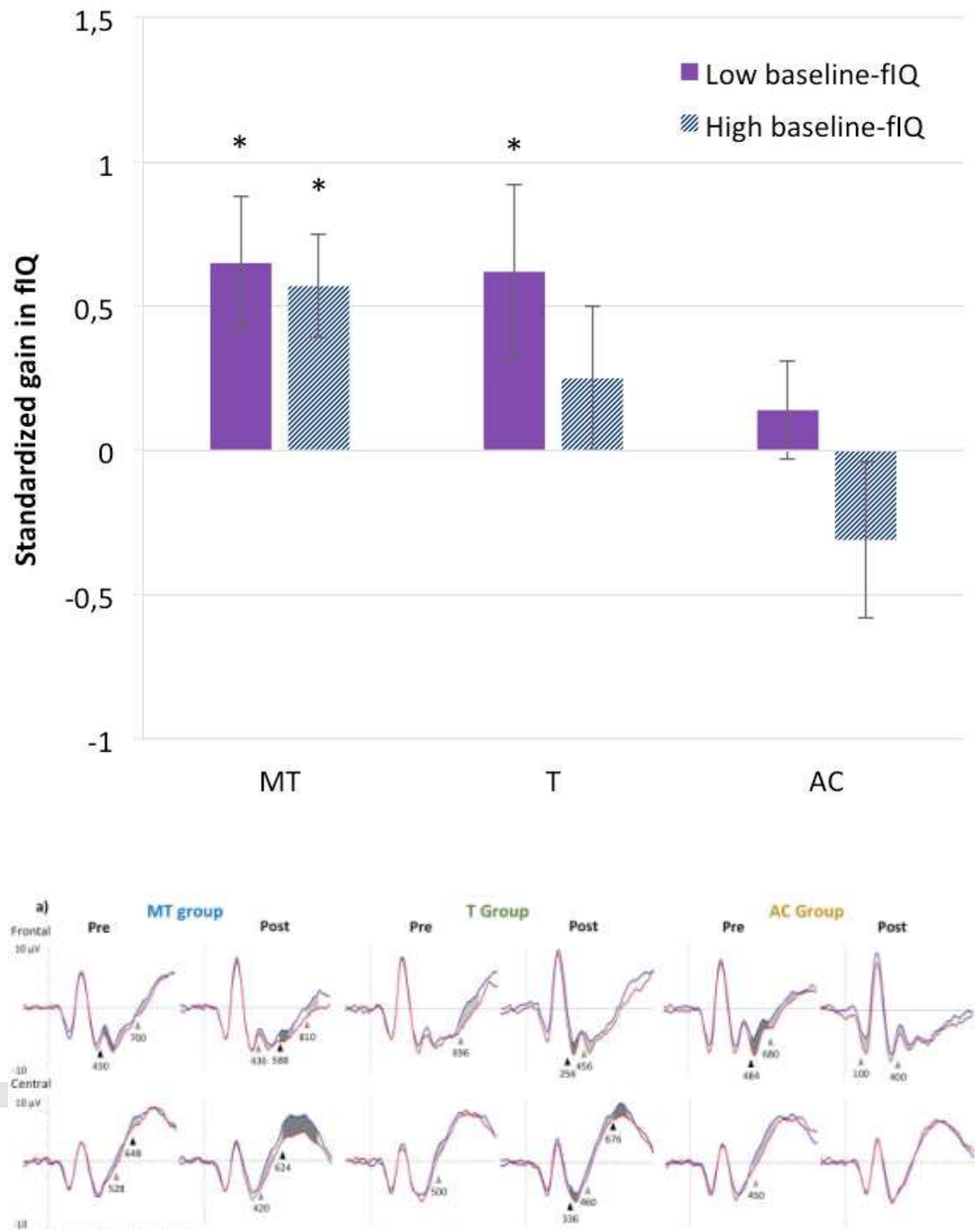

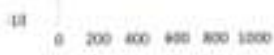

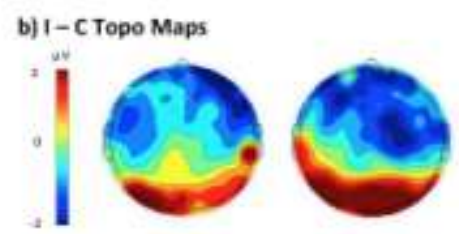

- Congrvent - inconeruen
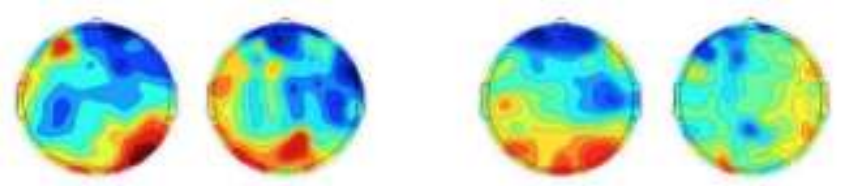

c)
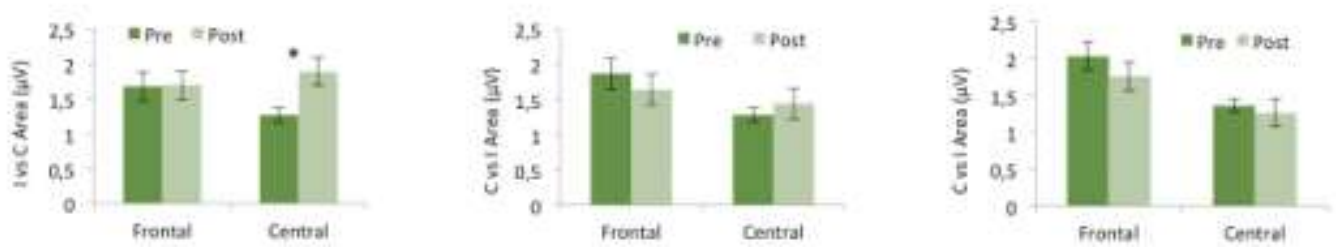

This article is protected by copyright. All rights reserved. 


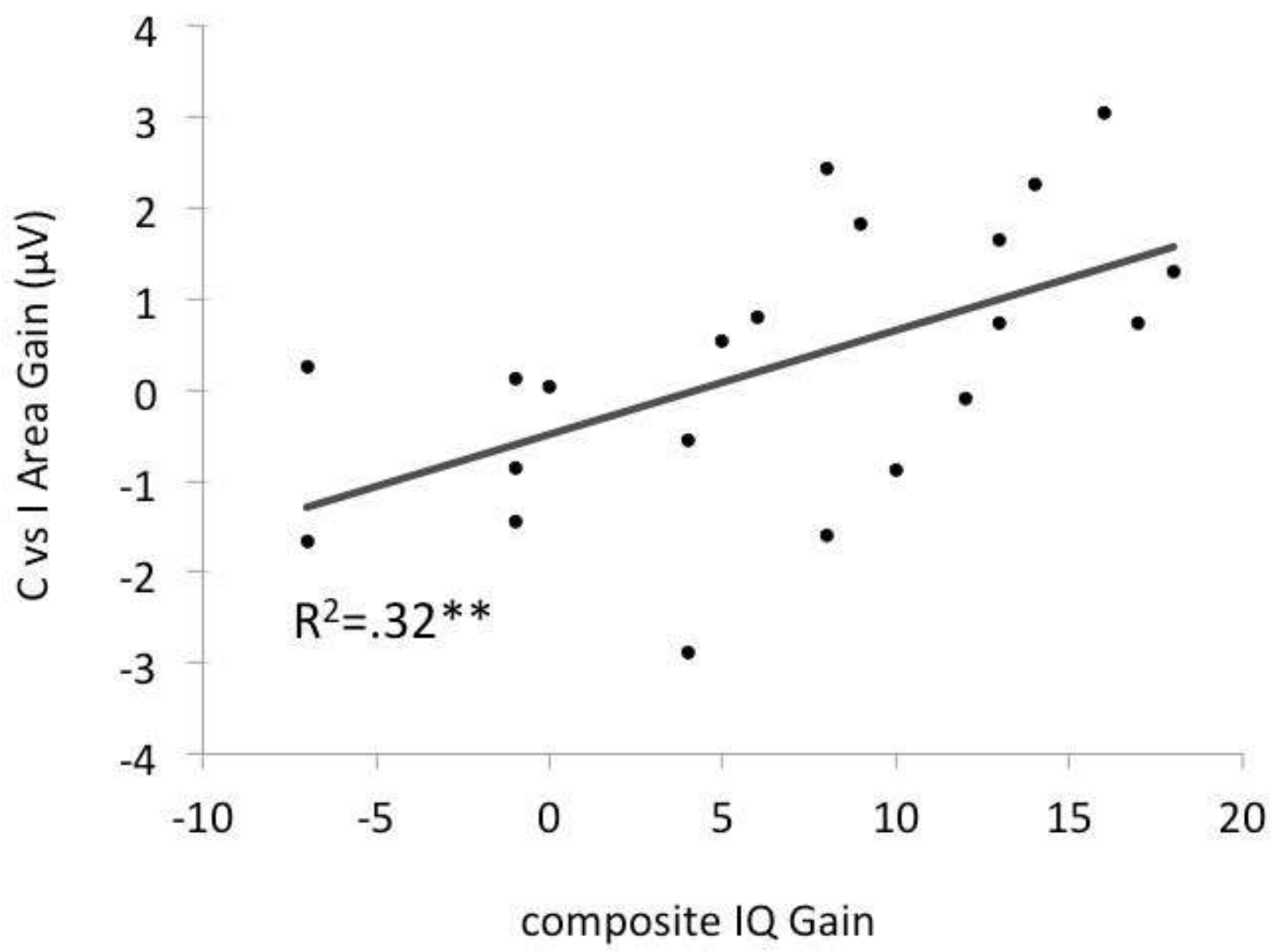

This article is protected by copyright. All rights reserved. 